\title{
Thermophysical Property Models for Lunar Regolith
}

\author{
Samuel S. Schreiner ${ }^{1, *}$ \\ Massachusetts Institute of Technology, 77 Massachusetts Avenue, Cambridge, MA 02139 \\ Jesus A. Dominguez ${ }^{2}$, Laurent Sibille ${ }^{3,}$ \\ NASA Kennedy Space Center, Florida 32899 \\ Jeffrey A. Hoffman ${ }^{4}$, \\ Massachusetts Institute of Technology, 77 Massachusetts Avenue, Cambridge, MA 02139
}

\begin{abstract}
We present a set of models for a wide range of lunar regolith material properties. Data from the literature are fit with regression models for the following regolith properties: composition, density, specific heat, thermal conductivity, electrical conductivity, optical absorption length, and latent heat of melting/fusion. These models contain both temperature and composition dependencies so that they can be tailored for a range of applications. These models can enable more consistent, informed analysis and design of lunar regolith processing hardware. Furthermore, these models can be utilized to further inform lunar geological simulations. In addition to regression models for each material property, the raw data is also presented to allow for further interpretation and fitting as necessary.
\end{abstract}

Keywords: lunar regolith, material property, models, electrical conductivity, density, specific heat, thermal conductivity, latent heat of melting, ISRU, In Situ Resource Utilization

\footnotetext{
${ }^{*}$ Corresponding author

Email address: schr0910@umn.edu (Samuel S. Schreiner)

${ }^{1}$ NASA Space Technology Research Fellow, MIT Department of Aeronautics and Astronautics

${ }^{2}$ VENCORE-ESC, NASA Kennedy Space Center

${ }^{3}$ Surface Systems Group, ESC-5, NASA Kennedy Space Center

${ }^{4}$ Professor of the Practice, MIT Department of Aeronautics and Astronautics
} 


\section{Introduction}

Although the lunar surface missions during the Apollo and Luna programs brought over $380 \mathrm{~kg}$ of lunar samples to Earth, significant uncertainty remains concerning the material properties of lunar regolith. These uncertainties have often impeded rigorous engineering design and analysis of hardware designed to interact with lunar regolith, including reactors to perform In-Situ Resource Utilization (ISRU) (Linne, 2010; Schreiner et al., 2015), pneumatic and mechanical regolith transport devices (Mueller et al., 2010; Standish, 2010), and regolith excavation devices (Zacny et al., 2009). Furthermore, uncertainty concerning regolith material properties affects simulations of lunar geological evolution (Snyder et al., 1994) and predictions of the concentration of solar-wind implanted volatiles in lava flows (Fagents et al., 2010).

Although the Lunar Sourcebook (Heiken et al., 1991) and other encyclopedias on the Moon (Badescu, 2012) contain extensive data on lunar regolith, they focus on understanding the scientific theory behind regolith material properties. Additionally, many critical properties, including specific heat, thermal conductivity, and electrical conductivity are not discussed in detail. These sources present excellent compilations of the theory behind some of the trends seen in Apollo data, but do not serve as engineering references for accessible functional models of lunar regolith properties.

Here we present a set of lunar regolith material property models for the density, specific heat, latent heat of melting, thermal conductivity, electrical conductivity, optical absorption length, Gibbs Free Energy, and Enthalpy of Formation. These models are rooted in data from hundreds of minerals including Apollo samples and analogous materials published in over 25 different articles in the literature. The models describe how regolith material properties depend on temperature, a critical aspect in many thermal-driven engineering applications, especially within the field of ISRU. The models are not limited to solid, granular regolith only, but also extend to the molten (liquid) state. Rumpf et al. (2013) pointed out that "[regolith] properties have rarely been measured at temperatures greater than 350K. Thus, the temperature dependencies of regolith properties must be extrapolated from measured values." By incorporating high-temperature data from lunar regolith analogs and simulants, we provide a measure of fidelity for the models in high tem- 
perature applications.

Furthermore, the majority of the models presented herein are differentiated based on the type of lunar regolith. That is, separate models are presented for Highlands, High-Ti Mare, and Low-Ti Mare lunar regolith. This dichotomy allows the models to be tailored to specific lunar applications, while also providing a degree of understanding as to how each material property is affected by regolith composition.

Although regression models are created for each regolith material property, the raw data from the literature survey is also presented in appendices so that additional analysis and data fitting may be performed as necessary.

\section{Types of Lunar Regolith}

Lunar regolith is comprised of minerals such as plagioclase, pyroxene, olivine, and ilmenite, and the concentration of each depends heavily upon location on the lunar surface (Heiken et al., 1991). Each of these minerals are composed of a number of oxide species, including iron(II) oxide (FeO), silica $\left(\mathrm{SiO}_{2}\right)$, alumina $\left(\mathrm{Al}_{2} \mathrm{O}_{3}\right)$, titania $\left(\mathrm{TiO}_{2}\right)$, magnesia $(\mathrm{MgO})$, calcium oxide $(\mathrm{CaO})$, and trace amounts of other minerals and elements.

Heiken et al. (1991) presents a dichotomy of lunar regolith into two broad categories: Mare (or Maria) and Highlands regolith. Mare regolith contains less plagioclase, but more olivine, pyroxene, and ilmenite. Stoeser et al. (2010) further divided Mare regolith into High-Titanium Mare ( $\geq 5 \mathrm{wt} \%$ $\left.\mathrm{TiO}_{2}\right)$ and Low-Titanium Mare $\left(<5 \mathrm{wt} \% \mathrm{TiO}_{2}\right)$ classifications. The oxide composition data presented in Stoeser et al. (2010) was averaged within each regolith type to generate a single value that represents the expected average composition for each regolith type.

Figure 1 shows the average composition data for each regolith type along with a map of the lunar surface with the lunar High-Ti Mare (yellow), LowTi Mare (cyan) and Highlands (older formations in red, younger formations in blue), from the Clementine UVVIS instrument (Lucey et al., 2000). The composition data is also presented in Table A.7. The regolith material properties presented herein are, to the largest extent possible, differentiated based upon regolith type.

\section{Density}

The bulk density of lunar regolith plays a large role in many engineering applications, as it drives the relationship between the regolith mass and vol- 


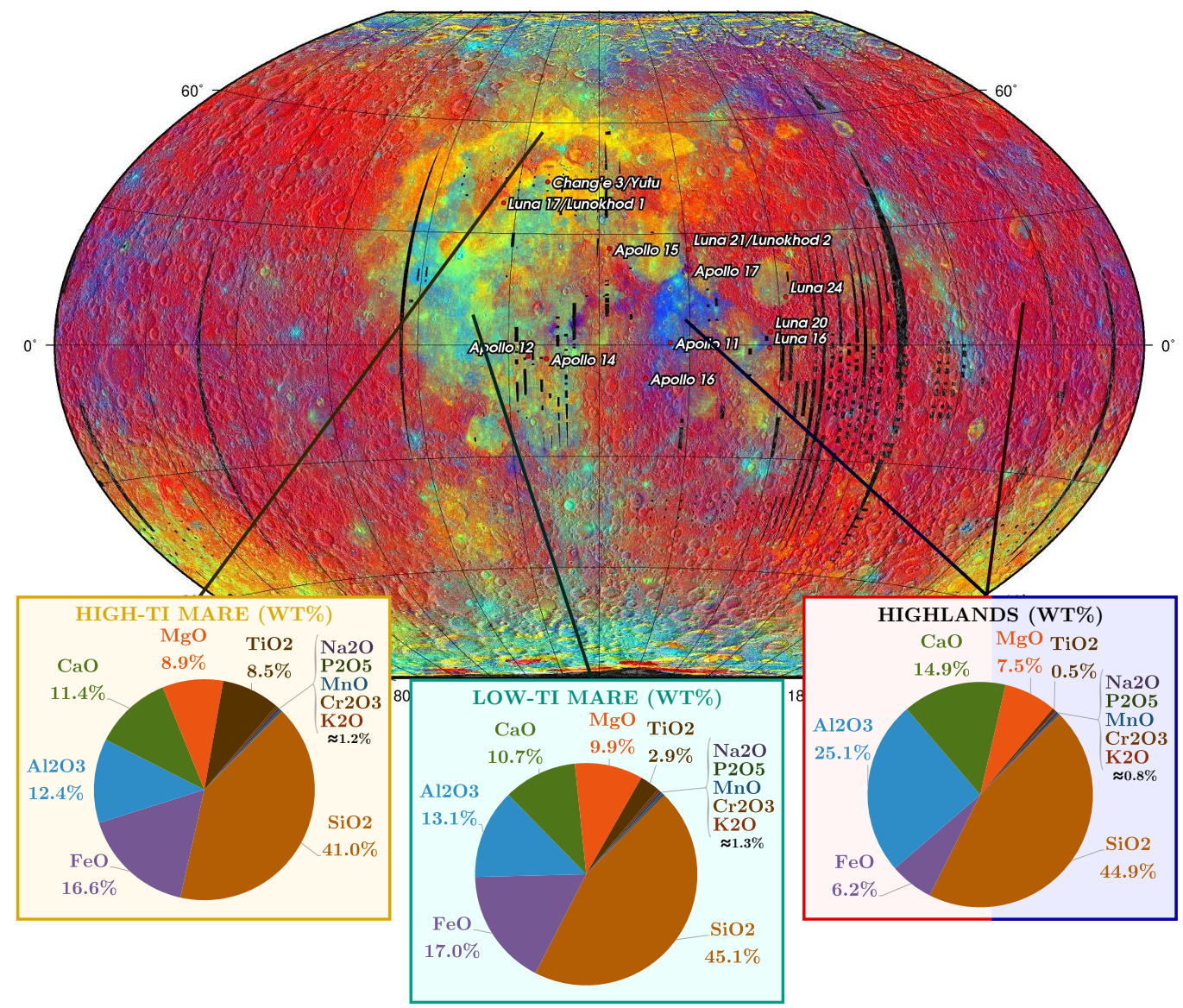

Figure 1: The composition of three different tyeps of lunar regolith: High-Titanium Mare (yellow), Low-Titanium Mare (cyan), and Highlands (older rock in red, younger rock in blue). Composition data from Apollo and Luna missions (Stoeser et al., 2010) and imagery data from Clementine UVVIS instrument (Lucey et al., 2000).

ume. This relationship is critical in sizing hardware elements such as regolith hoppers, reactors, and excavators. Additionally, density affects the modeling of lunar geological processes (Fagents et al., 2010).

The density of granular lunar regolith depends upon depth and compaction, but an average value of $1500 \mathrm{~kg} / \mathrm{m}^{3}$ appears to be appropriate (Heiken et al., 1991). This value is grounded in data for the top $15 \mathrm{~cm}$ of lunar soil samples from Apollo and Luna missions. Naturally, the expected density will rise with depth, though this value appears to be bounded below $1790 \mathrm{~kg} / \mathrm{m}^{3}$ for soil as deep as $60 \mathrm{~cm}$ (Heiken et al., 1991). 
For molten lunar regolith, the density varies with both temperature and composition. The model from Stebbins et al. (1984) for the volume of molten silicates was algebraically manipulated to create a density model. This model contains a dependence on both composition and temperature, allowing it to differentiate based on the compositions presented in Section 2. The model, shown in Equation (1), was used for the density of each of the three types of molten lunar regolith:

$$
\rho=\frac{r_{1}}{r_{2}+r_{3}(T-1873)}
$$

where $\rho$ is the density $\left(\mathrm{kg} / \mathrm{m}^{3}\right), T$ is the temperature $(\mathrm{K})$, and $r_{i}$ are regression coefficients, shown in Table 1 . The regression coefficients were calculated by weighting the oxide-specific coefficients by the oxide molar fraction for each type of regolith. The oxide-specific coefficients are derived from a linear regression of data from several dozen molten silicates between $1673 \mathrm{~K}$ and 1873K (Stebbins et al., 1984).

Table 1: The coefficients for the Stebbins density model (Equation (1)) applied to three types of lunar regolith.

\begin{tabular}{lccc} 
& $\mathbf{r}_{1}$ & $\mathbf{r}_{2}$ & $\mathbf{r}_{3}$ \\
\hline Highlands & $6.345 \times 10^{4}$ & 24.11 & 0.001206 \\
High-Ti Mare & $6.333 \times 10^{4}$ & 22.48 & 0.001982 \\
Low-Ti Mare & $6.384 \times 10^{4}$ & 23.01 & 0.001612 \\
\hline
\end{tabular}

The predictions from the density model are shown in Figure 2 for all three types of lunar regolith. The Mare regolith variants have a higher predicted density than the Highlands, due to the relatively larger concentration of $\mathrm{TiO}_{2}$ in Mare regolith compared to the relatively larger concentration of $\mathrm{Al}_{2} \mathrm{O}_{3}$ in Highlands regolith (see Figure 1). The relatively higher density for Mare regolith compared to anorthite-rich Highlands also aligns with the trends from Arndt et al. (1979). The values predicted by the model compare well with the range of 2490 to $2890 \mathrm{~kg} / \mathrm{m}^{3}$ measured for molten JSC-1A lunar simulant (Kallerud et al., 2011). Furthermore, the general decrease in density with temperature agrees well with the trends for melts with significant amounts of $\mathrm{SiO}_{2}, \mathrm{CaO}, \mathrm{MgO}, \mathrm{FeO}$, and $\mathrm{Al}_{2} \mathrm{O}_{3}$ (Eisenhüttenleute, 1995). 


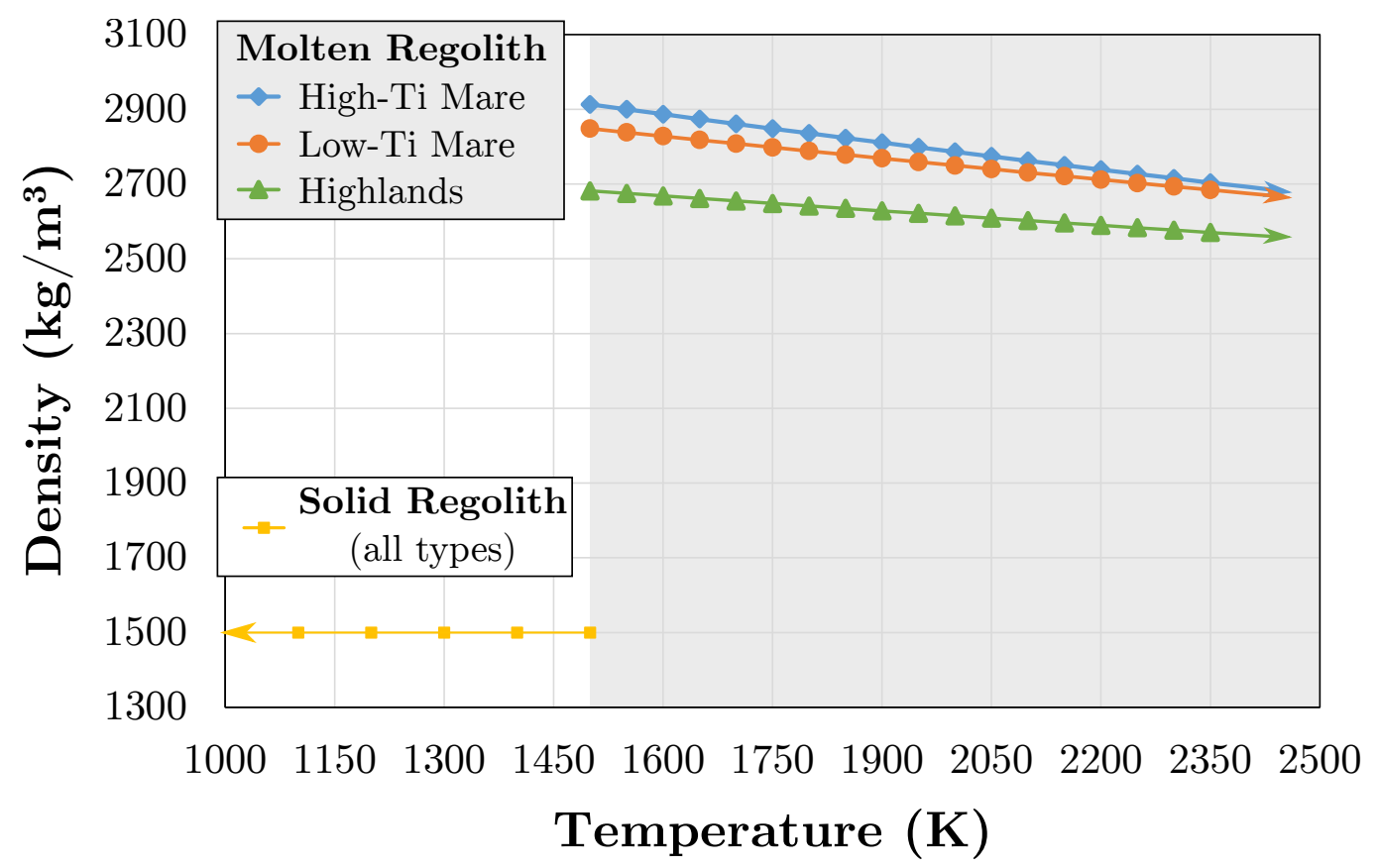

Figure 2: The variation of lunar regolith density with temperature. The density of solid regolith (for all types) is taken from Heiken et al. (1991) and the density molten lunar regolith (differentiated or High-Ti Mare, Low-Ti Mare and Highlands) is calculated using the density model from Stebbins et al. (1984).

\section{Specific Heat}

Many regolith processing systems require heating regolith from ambient to significantly higher temperatures (Taylor and Carrier III, 1992). To accurately predict the power requirements for regolith heating, the specific heat over the relevant temperature range must be well known.

For temperatures below $350 \mathrm{~K}$, a fourth-order polynomial fit of data from samples Apollo 14, 15, and 16 (Hemingway et al., 1973) was used:

$$
C_{p}=c_{a}+c_{b} T+c_{c} T^{2}+c_{d} T^{3}+c_{e} T^{4},
$$

where $C_{p}$ is the specific heat (in $\mathrm{J} /(\mathrm{kg}-\mathrm{K})$ ), $T$ is the temperature (in $\mathrm{K}$ ), $A$, $B, C, D$, and $E$ are regression coefficients from Hemingway et al. (1973):

For solid regolith above $350 \mathrm{~K}$, a model for silicate minerals from Stebbins et al. (1984) was employed to predict the heat capacity:

$$
C_{p}=\sum_{i} \chi_{i} c_{f, i}+T \sum_{i} \chi_{i} c_{g, i}+T^{-2} \sum_{i} \chi_{i} c_{h, i}
$$


Table 2: The coefficients for the specific heat of lunar regolith model between 100K and 350K from Hemingway et al. (1973).

$$
\begin{array}{ccccc}
c_{a} & c_{b} & c_{c} & c_{d} & c_{e} \\
\hline-2.317 \times 10^{-2} & 2.127 \times 10^{-3} & 1.501 \times 10^{-5} & -7.370 \times 10^{-8} & 9.655 \times 10^{-11} \\
\hline
\end{array}
$$

where $\chi_{i}$ is the mole fraction of oxide specie $i$ in lunar regolith, and $c_{f, i}$, $c_{g, i}$, and $c_{h, i}$ are coefficients derived from linear regression of data from several dozen minerals (Stebbins et al., 1984). Table 3 shows the resultant coefficients, calculated by weighting the oxide-specific coefficients by molar fraction.

For molten regolith, the specific heat remains relatively constant with temperature but varies with composition, as predicted by Stebbins et al. (1984):

$$
C_{p}=\sum_{i} \chi_{i} C_{l, i}
$$

where $C_{l, i}$ is the coefficient of oxide specie $i$ in lunar regolith, formed from a linear regression of a database of 58 different compositions (Stebbins et al., 1984). The resultant weighted coefficients are shown in the right-hand column in Table 3.

Table 3: The coefficients for the Stebbins heat capacity model (Equations (3) and (4)), in which oxide-specific coefficients are weighted by molar fraction. The summation represents a summation over all oxide species in lunar regolith.

\begin{tabular}{lcccc} 
& $\sum_{i} \chi_{i} c_{f, i}$ & $\sum_{i} \chi_{i} c_{g, i}$ & $\sum_{i} \chi_{i} c_{h, i}$ & $\sum_{i} \chi_{i} C_{l, i}$ \\
\hline High-Ti Mare & $8.820 \times 10^{2}$ & $3.083 \times 10^{-1}$ & $-2.278 \times 10^{7}$ & $1.531 \times 10^{3}$ \\
Low-Ti Mare & $9.093 \times 10^{2}$ & $2.870 \times 10^{-1}$ & $-2.469 \times 10^{7}$ & $1.539 \times 10^{3}$ \\
Highlands & $9.530 \times 10^{2}$ & $2.524 \times 10^{-1}$ & $-2.645 \times 10^{7}$ & $1.565 \times 10^{3}$ \\
\hline
\end{tabular}

The piecewise specific heat model from Equations (2), (3), and (4) are shown together in Figure 3. The data from Hemingway et al. (1973), also given in Table A.8, shows little variation based on the three different Apollo missions, as seen in the bottom right of Figure 3. The model from Stebbins et al. (1984) compares reasonably well with the Apollo data near 350K. The specific heat increases by an average of $248 \mathrm{~J} / \mathrm{kg}-\mathrm{K}$ at the melting temperature $(1500 \mathrm{~K})$, which compares quite well with the value of $243 \mathrm{~J} / \mathrm{kg}-\mathrm{K}$ observed across a wide range of minerals by Arndt et al. (1979). The predictions for molten lunar regolith are in the range of $1460-1700 \mathrm{~J} / \mathrm{kg}-\mathrm{K}$ cited 
by Fagents et al. (2010). The data in Figure 3 falls between the curves from Colozza (1991) and lunar simulant FJS-1, fabricated by the Japanese Aerospace Agency (Wakabayashi and Matsumoto, 2006). Data on the specific heat of FJS-1 is also shown in Table A.9.

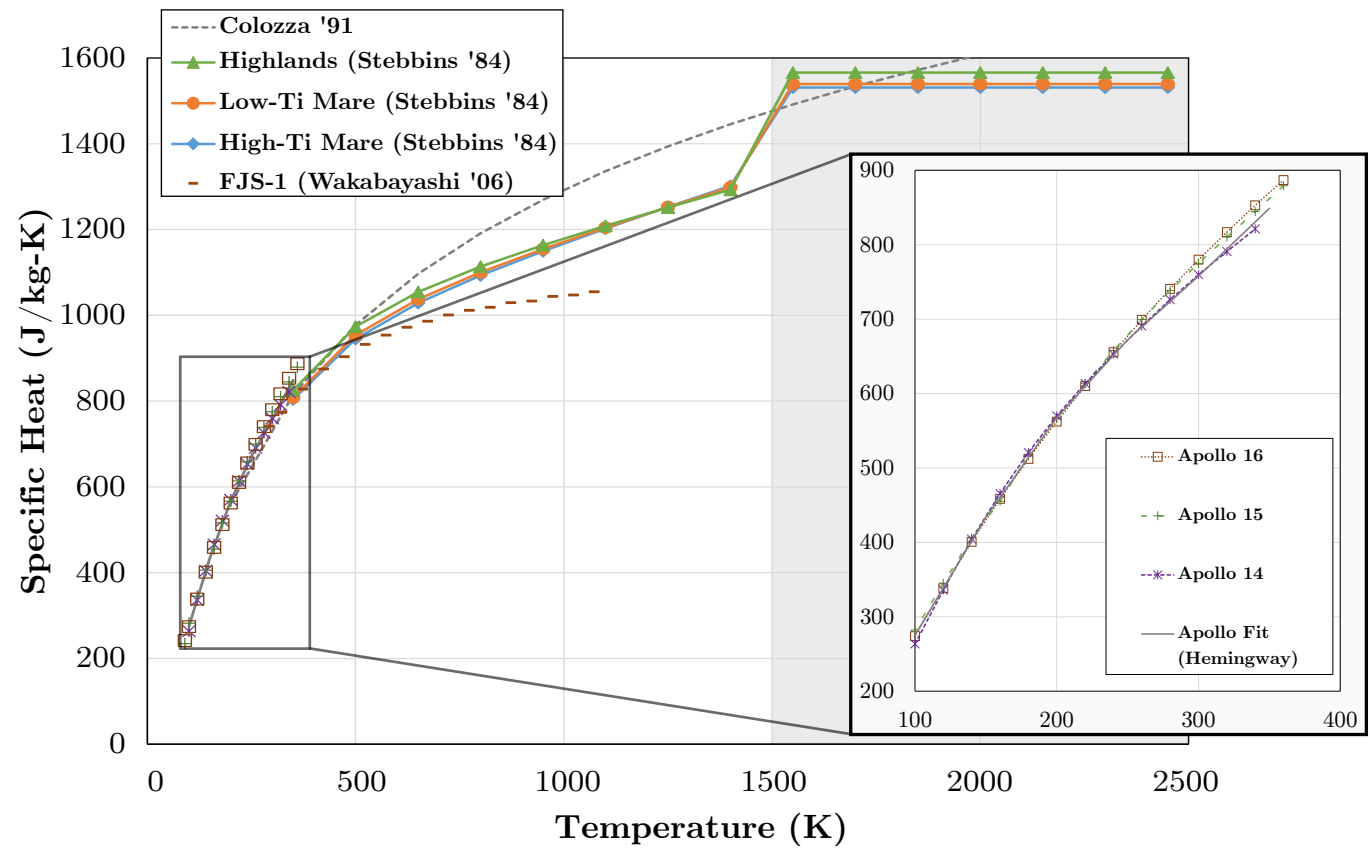

Figure 3: The specific heat model for lunar regolith. In the lower temperature regime $(\leq 350 \mathrm{~K})$, a fit from Hemingway et al. (1973) based on Apollo data is used. At higher temperatures $(>350 \mathrm{~K})$, a model by Stebbins et al. (1984) is used.

\section{Latent Heat of Melting}

The latent heat of melting (also known as latent heat of fusion) is a critical parameter in predicting the power requirements of systems that processes molten regolith (Solomon et al., 1992; Schreiner et al., 2015). Additionally, the latent heat of melting plays a significant role in modeling the cooling of lunar lava flows (Rumpf et al., 2013).

The latent heat of melting naturally depends on regolith composition and therefore regolith type. The modal mineralogical distribution of plagioclase, olivine, pyroxene, and ilmenite from Basu and Riegsecker (2000) is presented in Table 4 along with the latent heat of melting for each mineral from Richet 
and Bottinga (1986). To calculate the latent heat of melting for each regolith type, the latent heat of melting for each mineral was weighted by molar fraction, the results of which are shown in bold in the bottom row of Table 4 .

Table 4: The latent heat of melting for three different regolith types, calculated by weighting the latent heat of melting for four primary minerals (Richet and Bottinga, 1986) by molar fraction (Basu and Riegsecker, 2000).

\begin{tabular}{|c|c|c|c|c|}
\hline & \multicolumn{3}{|c|}{ Molar Fraction $\left(\chi_{i}\right)$} & \multirow{2}{*}{$\begin{array}{l}\text { Latent Heat of } \\
\text { Melting }(\mathrm{kJ} / \mathrm{mol})\end{array}$} \\
\hline & High-Ti Mare & Low-Ti Mare & Highlands & \\
\hline Plagioclase & 0.2830 & 0.2875 & 0.7320 & 134.3 \\
\hline Olivine & 0.0465 & 0.0880 & 0.0230 & 83.2 \\
\hline Pyroxene & 0.5945 & 0.5890 & 0.2440 & 65.1 \\
\hline Ilmenite & 0.0760 & 0.0355 & 0.0010 & 21.7 \\
\hline $\begin{array}{c}\text { Latent Heat } \\
(\mathrm{kJ} / \mathrm{kg})\end{array}$ & 449.2 & 457.7 & 478.6 & \\
\hline
\end{tabular}

As shown in Table 4, the latent heat of melting for lunar regolith is in the range 450-480 kJ/kg, depending on regolith type. These values compare are slightly below the reported range of $476-506 \mathrm{~kJ} / \mathrm{kg}$ for similar minerals analyzed by Kojitani and Akaogi (1995), likely due to differences in composition. These predictions are slightly higher than the value derived from Colozza (1991) of $400 \mathrm{~kJ} / \mathrm{kg}$ (calculated by integrating the value of $1.429 \mathrm{~kJ} / \mathrm{kg}-\mathrm{K}$ over the melting range of $1373-1653 \mathrm{~K}$ ). Although data concerning the latent heat of melting of lunar regolith is is relatively sparse, Fagents et al. (2010) notes that values near $500-600 \mathrm{~kJ} / \mathrm{kg}$ seem appropriate for basaltic compositions similar to lunar regolith. It is worth noting that the values reported here are significantly higher than the value reported for lunar simulant MLS1 of $161.2 \mathrm{~kJ} / \mathrm{kg}$ (Richter, 1992), although this value is for a sample size of $33.2 \mathrm{mg}$ and the uncertainty on this value is unknown.

\section{Thermal Conductivity}

The thermal conductivity of lunar regolith naturally plays a large role in modeling thermal transport. Thermal conductivity affects the expected thermal performance of reactors, and double-walled hoppers and augers intended to act as heat exchangers (Linne, 2010). The thermal conductivity also affects simulations of lunar lava flows and geological evolution (Fagents et al., 2010). 
For the thermal conductivity of solid lunar regolith, data from the FJS1 lunar simulant (Wakabayashi and Matsumoto, 2006) and Apollo samples (Langseth Jr et al., 1972; Cremers, 1975) was used. Data for FJS-1 are an order of magnitude higher than most the Apollo data. It is possible that the FJS-1 data comes from experiments with an overhead atmosphere (it is not specified in the report), which has been shown to increase the thermal conductivity of granular materials by an order of magnitude (Horai, 1981). The data from the Apollo 15 in-situ drilling experiment (Langseth Jr et al., 1972) is also higher than that of the other Apollo experiments. This is likely due to the fact that the thermal conductivity of the top layer is significantly lower than that of the lower regolith below $2 \mathrm{~cm}$ (Heiken et al., 1991). A careful examination is necessary to find the appropriate data for a particular application.

Thermal conductivity data was unavailable for molten lunar regolith, so a set of similar minerals were selected from Eisenhüttenleute (1995), Snyder et al. (1994), and Kang and Morita (2006). These selected species were representative of the large concentrations of $\mathrm{SiO}_{2}, \mathrm{CaO}, \mathrm{Al}_{2} \mathrm{O}_{3}, \mathrm{MgO}$ and $\mathrm{FeO}$ (more commonly $\mathrm{Fe}_{2} \mathrm{O}_{3}$ in terrestrial minerals) present in lunar regolith.

The combined data for solid and molten lunar regolith is presented in Figure 4 and shown in Tables A.10, A.11, A.12, and A.13. Note that the Apollo data in the figure is from regression fits of the sample data. The thermal conductivity for solid, granular regolith rises with temperature because granular, porous materials in vacuum will have two primary heat transfer mechanisms. The first is solid conduction through the particles and their contact surfaces, and the second is radiation in the inter-granular cavities. Watson (1964) first modeled this phenomenon using a constant for the conduction term with a third-order dependence on temperature to approximate complex emission-absorption radiative mechanism. This model has been used in the vast majority of work on the thermal conductivity of solid granular lunar regolith (Langseth Jr et al., 1972; Cremers, 1975) and was fit to the solid data (adjusted $\mathrm{R}^{2}=0.86, \mathrm{RMSE}=0.0090 \mathrm{~W} / \mathrm{m}-\mathrm{K}$ ):

$$
k=0.001561+5.426 \times 10^{-11}\left(T^{3}\right),
$$

where $k$ is the thermal conductivity $(\mathrm{W} / \mathrm{m}-\mathrm{K})$ and $T$ is the temperature $(\mathrm{K})$.

As seen in the right of Figure 4, the data for molten silicates similar to lunar regolith exhibits a decrease in thermal conductivity with temperature. Following the example of Kang and Morita (2006), the equation below was 


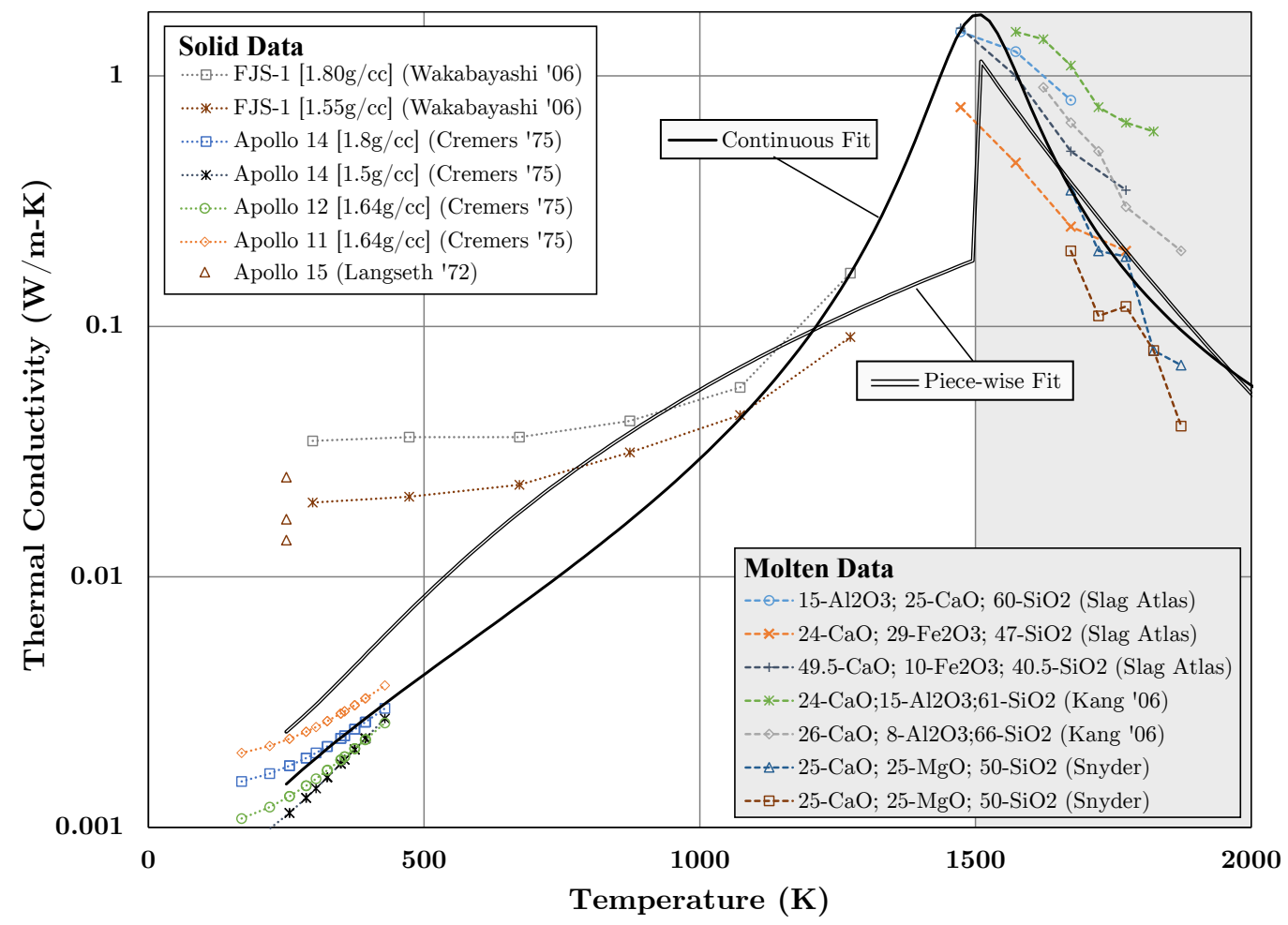

Figure 4: The thermal conductivity data for solid lunar regolith simulant FJS-1 (Wakabayashi and Matsumoto, 2006) and liquid silicates similar to lunar regolith (Eisenhüttenleute, 1995; Snyder et al., 1994).

fit to the molten data (adjusted $\mathrm{R}^{2}=0.67, \mathrm{RMSE}=0.43 \mathrm{~W} / \mathrm{m}-\mathrm{K}$ ):

$$
k=\exp \left(-9.332+\frac{1.409 \times 10^{4}}{T}\right)
$$

The low $\mathrm{R}^{2}$ value is due to the wide spread in the data due to composition. Future work can address differentiating the thermal conductivity model based on regolith composition and type.

As shown in Figure 4, the piece-wise model from Equation (5) and (6) exhibits a clear discontinuity at the melting temperature $(1500 \mathrm{~K})$. In reality, portions of regolith will exist in the molten and solid states in the vicinity of the melting temperature, smoothing out this discontinuity. Furthermore, piecewise functions often impede the convergence of simulations in which the phase transition must be modeled (Schreiner et al., 2015). To this end, a empirical continuous model was fit over both the solid and molten data. 
This continuous model, illustrated by the solid black line in Figure 4, was chosen as it provides rapid simulation convergence:

$$
k=\frac{0.01257\left(T^{\prime}\right)+0.0172}{\left(T^{\prime}\right)^{2}-2.874\left(T^{\prime}\right)+2.085},
$$

where $T^{\prime}$ is the temperature in $\mathrm{K}$ normalized by a mean 691.7 and standard deviation 564.3 (adjusted $\mathrm{R}^{2}=0.96, \mathrm{RMSE}=0.096 \mathrm{~W} / \mathrm{m}-\mathrm{K}$ ). Overall, the trends observed in the continuous regression fit are in agreement with those observed in the range of minerals in Slag Atlas (Eisenhüttenleute, 1995). The appropriate model, whether continuous or piecewise, must be chosen based upon application.

\section{Electrical Conductivity}

The electrical conductivity of lunar regolith affects performance predictions for electrochemical reactors (Schreiner et al., 2015) and plays a role in simulating geophysical aspects of the lunar interior (Olhoeft et al., 1974).

For solid lunar regolith, the electrical conductivity is expected to be close to zero. Electrical conductivity data directly from Apollo samples 12002,85 and 65015,6 was utilized (Olhoeft et al., 1974). For molten lunar regolith, data was utilized from a lunar regolith analog with a composition of $25 \%$ $\mathrm{CaO}, 25 \% \mathrm{MgO}$, and $50 \% \mathrm{SiO} 2$ with varying amounts of $\mathrm{FeO}$ added (Ducret et al., 2002). The mixture with $5 \mathrm{wt} \% \mathrm{FeO}$ added was used to approximate both Mare types of regolith and data for the melt with $15 \mathrm{wt} \% \mathrm{FeO}$ added was used for the Highlands, to match the compositions shown in Figure 1. Additional data on iron-rich basalt from Carroll (1983) was used for Mare regolith. Figure 5 shows the electrical conductivity data combined from all of these sources, which is also presented in Table A.14.

Intuitively, solid granular lunar regolith has a much lower electrical conductivity than the molten state. Starting around the glass transition temperature, which is around 2/3 of the melting temperature (Vila et al., 2006) or $1000 \mathrm{~K}$, the electrical conductivity begins to rise noticeable above zero. This can be attributed to the increase in relaxation and transport mechanisms (Vila et al., 2006) and, at higher temperatures, the gradual transition from the solid to molten state. The increase in electrical conductivity past the melting point is due to the decrease in viscosity and subsequent rise in ionic mobility (Colson and Haskin, 1990), which is a primary driver of electrical conductivity in molten oxides (Schiefelbein and Sadoway, 1997). 


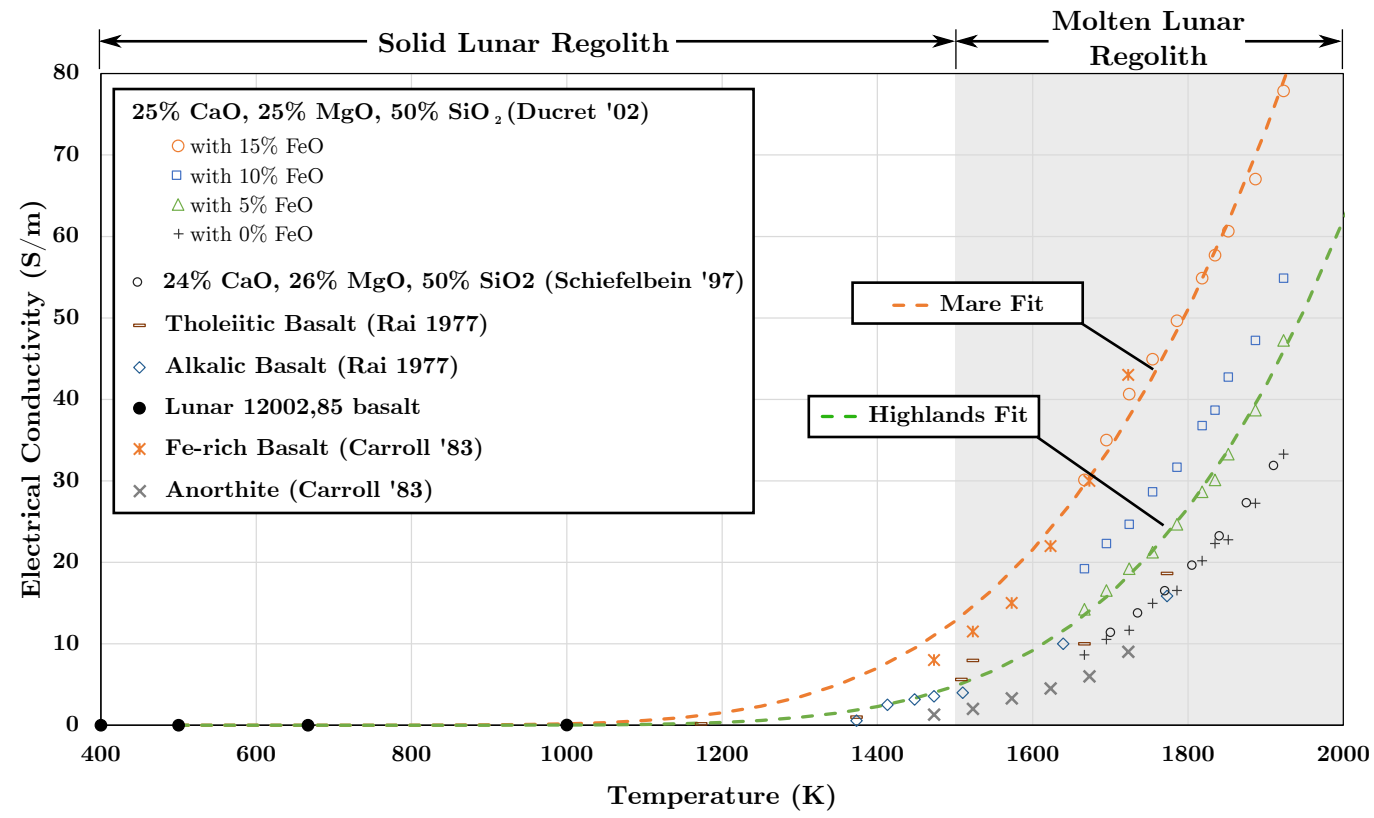

Figure 5: Data of electrical conductivity for lunar regolith and similar materials. A fit is overlaid for compositions similar to Highlands and Mare lunar regolith. The electrical conductivity begins increasing around the melting temperature due to increased ionic conductivity via a decrease in viscosity at higher temperatures.

The electrical conductivity data for both solid and molten regolith was fit with a Vogel-Tamman-Fulcher (VTF) equation (Vogel, 1925; Tamman and Heese, 1926; Fulcher, 1925), as it has been shown to match the temperature dependence of the electrical conductivity of ionic liquids quite well (Vila et al., 2006):

$$
\sigma_{e}=e_{a} \exp \left(\frac{-e_{b}}{T-T_{g}}\right)
$$

where $\sigma_{e}$ is the electrical conductivity (in $\mathrm{S} / \mathrm{m}$ ), $T$ is the temperature (in $\mathrm{K}), T_{g}$ is the glass transition temperature (often fit with regression analysis), and $e_{a}$ and $e_{b}$ are regression coefficients presented in Table 5 (adjusted $\mathrm{R}^{2}=$ 0.997). Note that $T_{g}$ had to be set to zero to avoid vertical asymptotes in the low temperature regime.

As observed in Figure 5, the model compares reasonably well with data for Tholeiitic and Alkali basalts (Rai, 1977), data on basalt and anorthite (Carroll, 1983), and data from Schiefelbein and Sadoway (1997). Clearly the electrical conductivity increases with $\mathrm{FeO}$ concentration, due to increased 
Table 5: The regression coefficients for the model of electrical conductivity of lunar regolith (Equation (8)), differentiated for Mare and Highlands regolith.

\begin{tabular}{ccc} 
& Mare & Highlands \\
\hline$e_{a}$ & $3.130 \times 10^{4}$ & $1.291 \times 10^{5}$ \\
$e_{b}$ & $1.154 \times 10^{4}$ & $1.528 \times 10^{4}$ \\
\hline
\end{tabular}

electronic conductivity of iron oxides (Sirk et al., 2010). In the context of lunar regolith, this means that one can expect a higher electrical conductivity for Mare regolith compared to Highlands.

Although a continuous fit over the solid and molten data enables rapid physical simulation across the phase boundary (Schreiner et al., 2015), this could possibly introduce some reduction in model fidelity (the VTF fit in Equation 8 is intended for ionic liquids rather than solids). To this end, regression fits of the data above $1500 \mathrm{~K}$ were compared to the regression fits for the full temperature range. Average discrepancies under $1 \%$ were observed between the two fits between 1500K and 2000K for both Highlands and Mare data, indicating that the full data regression fit can function well in the high temperature regime. For applications in which the electrical conductivity of solid regolith at low temperatures is of critical importance, the fit given by Equation (8) may not be appropriate. The reader is directed to the work of Olhoeft et al. (1974), which addresses the hysteresis observed in low temperature data and provides exponential fits of data from two Apollo samples. For applications in which the low temperature data must simply be significantly lower than the high temperature data (Schreiner et al., 2015), the model in Equation (8) is adequate.

\section{Optical Absorption Length}

For sintering and molten regolith processing, the optical absorption length affects radiative thermal transport through the semi-translucent medium (Sibille and Dominguez, 2012; Balasubramaniam et al., 2010).

Wavelength-dependent data on molten glasses from Sibille and Dominguez (2012) was first fit with a step function of $0.3 \mathrm{~cm}^{-1}$ for wavelengths below $2750 \mathrm{~nm}$ and $4 \mathrm{~cm}^{-1}$ above $2750 \mathrm{~nm}$. The upper value of the step function compares well with those of Arndt et al. (1979) for basalt and anorthosite samples at higher wavelengths, but the drop to lower absorption lengths at lower wavelengths remains to be validated. This step function was then 
weighted by the Planck black body energy density and integrated over all wavelengths to determine the average absorption length at a given temperature:

$$
\alpha(T)=\frac{\int_{0}^{\infty} P(\lambda, T) \alpha(\lambda) d \lambda}{\int_{0}^{\infty} P(\lambda, T) d \lambda},
$$

where $\alpha(\lambda)$ is the absorption coefficient as a function of wavelength, $\lambda$, and $P(\lambda)$ is the spectral energy density as a function of wavelength from Planck's Law (Planck, 1914):

$$
P(\lambda, T)=\frac{8 \pi h c^{2}}{\lambda^{5}}\left(\frac{1}{\exp \left(\frac{h c}{k_{B} T \lambda}\right)-1}\right),
$$

where $h$ is Planck's constant, $c$ is the speed of light, and $k_{B}$ is Boltzmann's constant.

The left plot in Figure 6 shows the step function for absorption length derived from Sibille and Dominguez (2012) (black solid line) overlaid with the Planck black body spectral energy density curve at two different temperatures, $700 \mathrm{~K}$ (blue) and $3000 \mathrm{~K}$ (red). The right plot in Figure 6 shows the resultant absorption length as a function of temperature $(\alpha(T)$ from Equation (9)) with a regression fit using a summation of five Gaussian functions:

$$
\alpha(T) \approx a_{1} e^{-\left(\frac{T-b_{1}}{c_{1}}\right)^{2}}+\cdots+a_{5} e^{-\left(\frac{T-b_{5}}{c_{5}}\right)^{2}}
$$

where $a_{i}, b_{i}$, and $c_{i}$ are regression coefficients shown in Table 6 (adjusted $\mathrm{R}^{2}$ $=0.999)$.

Table 6: The coefficients for the optical absorption length model (Equation (11)).

Gauss 1 Gauss 2 Gauss 3 Gauss 4 Gauss 5

\begin{tabular}{cccccc}
\hline $\mathbf{a}_{i}$ & 465 & -0.650 & 163 & 0.325 & 1.45 \\
$\mathbf{b}_{i}$ & -3670 & 200 & 528 & 175 & 150 \\
$\mathbf{c}_{i}$ & 5040 & 4.69 & 905 & 4.40 & 3.54 \\
\hline
\end{tabular}

The trends in the right-hand plot in Figure 6 reveal that the absorption length decreases at higher temperatures. The model presented here is based on absorption length data from molten glasses and the uncertainty concerning the absorption length of actual lunar regolith warrants further examination. Arndt et al. (1979) observed that basaltic droplets were essentially opaque while anorthositic droplets were semi-transparent. Future work can address differentiating the absorption length model based on regolith type. 

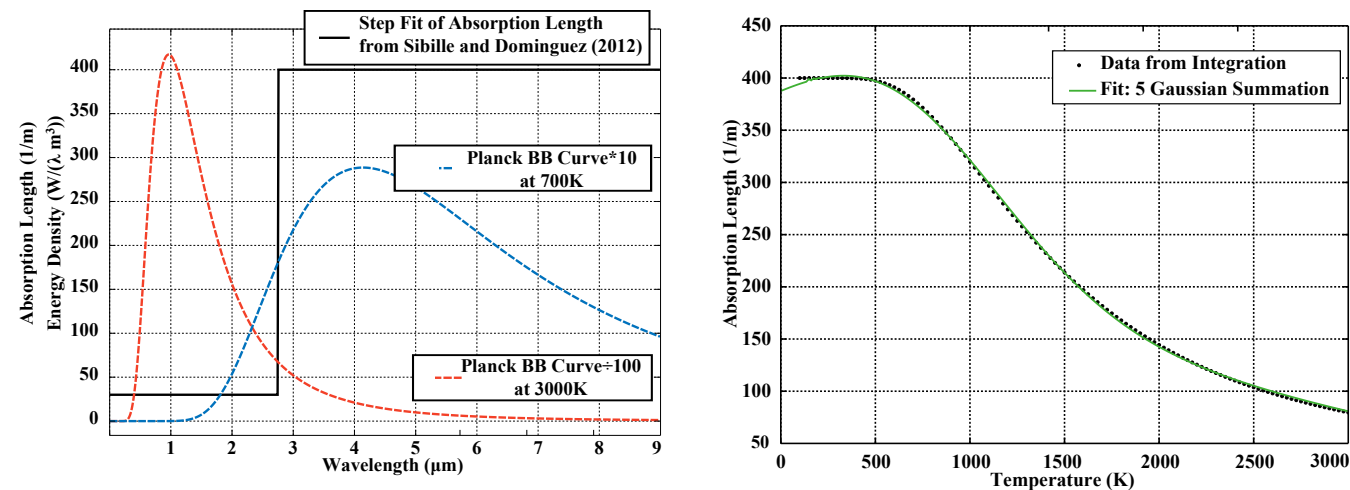

Figure 6: (left) Absorption length data from Sibille and Dominguez (2012) fit with a step function (black solid line) overlaid with the Planck black body spectral energy density at two different temperatures (dashed lines). (right) The wavelength-dependent step function was integrated over the Planck curve to calculate the average absorption length as a function of temperature.

\section{Gibbs Free Energy \& Enthalpy of Formation}

The Gibbs Free Energy $(\Delta \mathrm{G})$ and Enthalpy of Formation $(\Delta \mathrm{H})$ for the oxide species in lunar regolith describe the energy required to break the chemical bonds, a critical step in many regolith processing techniques, including Molten Regolith Electrolysis and Pyrolysis (Taylor and Carrier III, 1992). Data for these two values for each oxide specie in lunar regolith was obtained from the NIST-JANAF thermochemical tables (Chase and Force, 1998). Due to the fact that $\Delta \mathrm{G}$ and $\Delta \mathrm{H}$ often change with phase, the data was separated into high temperature and low temperature data and fit with the following equation (Chase and Force, 1998):

$$
\begin{aligned}
\Delta G(T) & =a_{G}+b_{G} T \log _{10}(T)+c_{G} T \\
\Delta H(T) & =a_{H}+b_{H} T,
\end{aligned}
$$

where $T$ is the temperature $(\mathrm{K})$ and $a_{G}, b_{G}, c_{G}, a_{H}$, and $b_{H}$ are regression coefficients for each oxide specie, shown in Table A.15. There is good agreement between the two intercepts $\left(a_{G}\right.$ and $\left.a_{H}\right)$, as one would expect.

Figure 7 shows the low temperature (solid lines) and high temperature (dashed lines) fits compared to the data. As one would expect, the Gibbs Free Energy rises significantly with temperature, while the Enthalpy of Formation remains relatively constant across a wide temperature range. The 

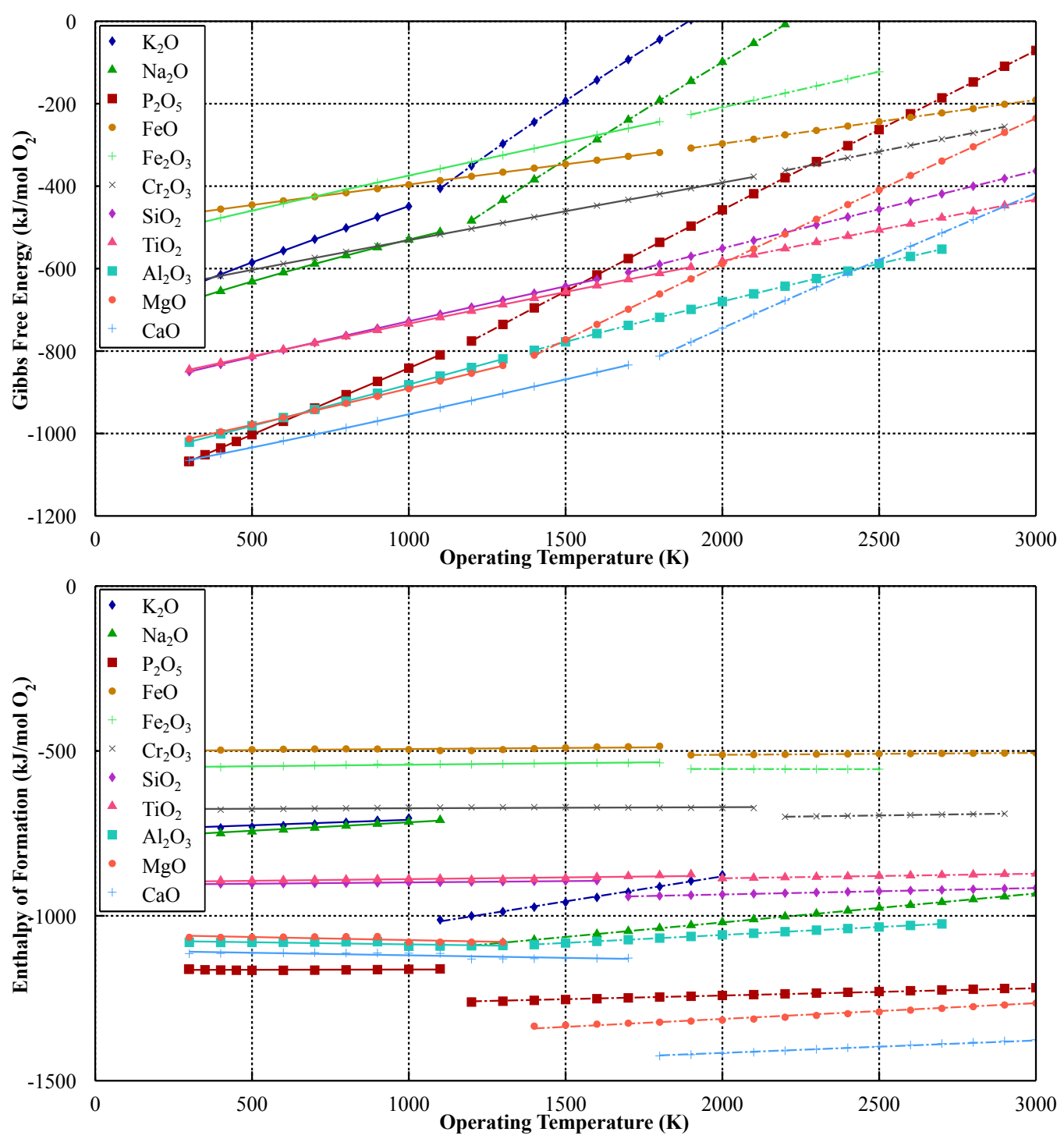

Figure 7: The Gibbs Free Energy (top) and Enthalpy of Formation (bottom) for each oxide specie in lunar regolith (Chase and Force, 1998), with linear fits over the high temperature data. 
Enthalpy of Formation data indicates that iron oxide (FeO) is the most attractive oxide specie for oxygen production from a chemical perspective, as it requires the least amount of energy to isothermally reduce to its base metal and oxygen. Titania $\left(\mathrm{TiO}_{2}\right)$ and silica $\left(\mathrm{SiO}_{2}\right)$ are the next most attractive targets, requiring slightly less than twice the energy of iron oxide. Alumina $\left(\mathrm{Al}_{2} \mathrm{O}_{3}\right)$, magnesia $(\mathrm{MgO})$, and calcium oxide $(\mathrm{CaO})$ present the least chemically attractive objects for reduction.

Although the source data for Gibbs Free Energy and Enthalpy of Formation is rooted in significant experimental work (Chase and Force, 1998), the values may need to be adjusted with activity coefficients based on the relative concentration of each oxide in lunar regolith, though the effect is not anticipated to significantly change these values.

\section{Conclusions}

In this work we present several models for the material properties of Highlands and Mare lunar regolith, including chemical composition, density, specific heat, latent heat of melting/fusion, thermal conductivity, electrical conductivity, optical absorption length, Gibbs Free Energy and the Enthalpy of Formation. These models incorporate a wide range of data from hundreds of minerals, including and Apollo and Luna samples as well as a vast array of lunar regolith analogs and simulants.

The data used to build the regolith material property models spans a wide temperature range $(\approx 100 \mathrm{~K}$ to $2000 \mathrm{~K})$, including both the solid and molten (liquid) states. By including high temperature data from lunar analogs, these models extend previous work significantly beyond the traditional range of 100-350K (Rumpf et al., 2013) and decrease the uncertainty of the hightemperature behavior of lunar regolith.

It is found that the density of molten lunar regolith varies significantly with temperature and regolith type (Highlands or Mare). The specific heat is within $5 \%$ for Highlands and Mare regolith, but varies significantly with temperature. The latent heat of melting (fusion) is slightly higher $(\approx 7 \%)$ in Highlands regolith due to the increased amount of plagioclase. The thermal conductivity varies widely depending upon the density, compaction, and temperature of regolith, though the effect of regolith composition/type is still uncertain. Electrical conductivity rises with temperature and is higher for Mare regolith due to the increased iron oxide concentration. The optical absorption length data is preliminary at best, but indicates that in high 
temperature molten regolith radiation may travel on the order of a few millimeters before being reabsorbed and scattered.

Future work can add more data to the data sets presented here. The behavior of lunar regolith around the glass transition temperature around 1000K also warrants additional investigation. Data on the optical absorption length are particularly sparse for lunar regolith and simulants. Electrical and thermal conductivity at high temperatures are also somewhat uncertain.

The regolith material property models presented herein can be used to inform the design and analysis of regolith processing hardware, such as excavators, ISRU reactors, and regolith transport devices. Furthermore, these models can also be leveraged to better inform simulation for lunar geological processes. This work extends significantly beyond previous data and models to enable a more informed understanding of the behavior of lunar regolith across a wide temperature range.

\section{Acknowledgments}

This work was supported by a NASA Space Technology Research Fellowship (Grant \#NNX13AL76H). Any opinions, findings, and conclusions or recommendations expressed in this material are those of the author and do not necessarily reflect the views of NASA. 


\section{Appendix A. Data Tables}

Table A.7: The weight percent and mole percent chemical compositions of lunar regolith, categorized in High-Ti Mare (HTM), Low-Ti Mare (LTM), and Highlands (HL).

\begin{tabular}{l|ccc|ccc}
\multirow{2}{*}{ Oxide Specie } & \multicolumn{3}{|c|}{ Weight Percent } & \multicolumn{3}{c}{ Mole Percent } \\
\cline { 2 - 7 } & HTM & LTM & HL & HTM & LTM & HL \\
\hline $\mathrm{K}_{2} \mathrm{O}$ & 0.2 & 0.1 & 0.8 & 0.2 & 0.2 & 0.1 \\
$\mathrm{Na}_{2} \mathrm{O}$ & 0.4 & 0.4 & 2.8 & 0.4 & 0.4 & 0.4 \\
$\mathrm{P}_{2} \mathrm{O}_{5}$ & 0.2 & 0.1 & 0.7 & 0.2 & 0.4 & 0.2 \\
$\mathrm{FeO}$ & 17.2 & 6.3 & 3.5 & 17.8 & 18.4 & 6.4 \\
$\mathrm{Cr}_{2} \mathrm{O}_{3}$ & 0.4 & 0.1 & 0.0 & 0.9 & 0.9 & 0.3 \\
$\mathrm{MnO}^{\mathrm{SiO}}$ & 0.2 & 0.1 & 0.2 & 0.2 & 0.2 & 0.1 \\
$\mathrm{TiO}_{2}$ & 45.4 & 45.0 & 47.5 & 36.7 & 40.8 & 38.8 \\
$\mathrm{Al}_{2} \mathrm{O}_{3}$ & 2.9 & 0.5 & 1.5 & 10.2 & 3.5 & 0.6 \\
$\mathrm{MgO}$ & 13.2 & 25.1 & 15.0 & 18.8 & 20.1 & 36.7 \\
$\mathrm{CaO}$ & 10.0 & 7.6 & 9.0 & 5.3 & 6.0 & 4.4 \\
\hline
\end{tabular}


Table A.8: Specific Heat data for lunar regolith from Apollo samples as reported by Hemingway et al. (1973).

\begin{tabular}{c|ccccc} 
& \multicolumn{5}{|c}{ Specific Heat $(\mathrm{J} / \mathrm{kg}-\mathrm{K})$} \\
\hline Temperature & \multicolumn{5}{|c}{ Lunar Sample Number } \\
$(\mathrm{K})$ & 14321,153 & 14163,186 & 15555,159 & 15301,20 & 60601,31 \\
\hline 90 & & & 228.9 & 240.6 & 241.8 \\
100 & 253.6 & 273.6 & 292.0 & 272.4 & 274.1 \\
120 & 322.6 & 349.4 & 354.8 & 335.6 & 338.5 \\
140 & 395.0 & 413.8 & 415.1 & 396.6 & 400.8 \\
160 & 459.0 & 472.4 & 472.0 & 438.5 & 458.6 \\
180 & 512.1 & 529.7 & 525.5 & 507.1 & 512.1 \\
200 & 558.6 & 581.2 & 575.7 & 557.3 & 562.3 \\
220 & 602.1 & 625.1 & 623.0 & 604.6 & 610.0 \\
240 & 643.5 & 662.7 & 666.9 & 648.9 & 655.6 \\
260 & 681.2 & 700.4 & 708.4 & 690.8 & 699.1 \\
280 & 715.0 & 737.6 & 746.8 & 730.1 & 740.6 \\
300 & 748.5 & 771.1 & 782.8 & 767.3 & 779.9 \\
320 & 783.2 & 798.7 & 817.1 & 803.7 & 817.1 \\
340 & 817.1 & 825.5 & 850.2 & 838.9 & 853.1 \\
360 & & & 886.2 & 872.4 & 887.0 \\
\hline
\end{tabular}

Table A.9: Data on the specific heat of lunar simulant FJS-1 (Wakabayashi and Matsumoto, 2006).

\begin{tabular}{cc|cc|cc}
$\begin{array}{c}\text { Temp. } \\
(\mathrm{K})\end{array}$ & $\begin{array}{c}\text { Sp. Heat } \\
(\mathrm{J} / \mathrm{kg}-\mathrm{K})\end{array}$ & $\begin{array}{c}\text { Temp. } \\
(\mathrm{K})\end{array}$ & $\begin{array}{c}\text { Sp. Heat } \\
(\mathrm{J} / \mathrm{kg}-\mathrm{K})\end{array}$ & $\begin{array}{c}\text { Temp. } \\
(\mathrm{K})\end{array}$ & $\begin{array}{c}\text { Sp. Heat } \\
(\mathrm{J} / \mathrm{kg}-\mathrm{K})\end{array}$ \\
\hline 293 & 741.6 & 573 & 954.0 & 873 & 1029.6 \\
323 & 774.0 & 623 & 972.0 & 923 & 1033.2 \\
373 & 828.0 & 673 & 986.4 & 973 & 1044.0 \\
423 & 874.8 & 723 & 1000.8 & 1023 & 1047.6 \\
473 & 903.6 & 773 & 1011.6 & 1073 & 1054.8 \\
523 & 932.4 & 823 & 1018.8 & & \\
\hline
\end{tabular}


Table A.10: (top rows) Thermal conductivity data from Apollo 12 samples (Cremers, 1975). (bottom row) Thermal conductivity data from the Apollo 15 drilling experiment at an estimated temperature of $250 \mathrm{~K}$ (Langseth Jr et al., 1972).

\begin{tabular}{cccccc} 
Temp. $(\mathrm{K})$ & $\mathrm{k}(\mathrm{W} / \mathrm{m}-\mathrm{K})$ & Temp. $(\mathrm{K})$ & $\mathrm{k}(\mathrm{W} / \mathrm{m}-\mathrm{K})$ & Temp. $(\mathrm{K})$ & $\mathrm{k}(\mathrm{W} / \mathrm{m}-\mathrm{K})$ \\
\hline 169 & 0.00114 & 325 & 0.00219 & 374 & 0.00270 \\
256 & 0.00121 & 349 & 0.00241 & 374 & 0.00278 \\
256 & 0.00129 & 349 & 0.00243 & 374 & 0.00283 \\
286 & 0.00161 & 349 & 0.00246 & 393 & 0.00259 \\
286 & 0.00161 & 356 & 0.00197 & 394 & 0.00268 \\
304 & 0.00207 & 356 & 0.00205 & 429 & 0.00339 \\
324 & 0.00180 & & & & \\
\hline \multicolumn{7}{c}{} \\
Depth $(\mathrm{m})$ & $\mathrm{k}(\mathrm{W} / \mathrm{m}-\mathrm{K})$ & Depth $(\mathrm{m})$ & $\mathrm{k}(\mathrm{W} / \mathrm{m}-\mathrm{K})$ & Depth $(\mathrm{m})$ & $\mathrm{k}(\mathrm{W} / \mathrm{m}-\mathrm{K})$ \\
\hline 0.49 & 0.014 & 0.91 & 0.017 & 1.38 & 0.025 \\
\hline
\end{tabular}

Table A.11: Regression fit coefficients from Cremers (1975) for Equation (5) for data from several Apollo samples and terrestrial basalt with a range of densities.

\begin{tabular}{ccccc} 
& Apollo 11 & Apollo 14 & Apollo 14 & Apollo 12 \\
\hline Density $\left(\mathrm{g} / \mathrm{cm}^{3}\right)$ & 1.64 & 1.50 & 1.80 & 1.64 \\
$\mathrm{k}_{A}(\mathrm{~W} / \mathrm{m}-\mathrm{K})$ & $1.87 \times 10^{-3}$ & $7.16 \times 10^{-4}$ & $1.43 \times 10^{-3}$ & $9.85 \times 10^{-4}$ \\
$\mathrm{k}_{B}\left(\mathrm{~W} / \mathrm{m}-\mathrm{K}^{4}\right)$ & $2.3 \times 10^{-11}$ & $2.54 \times 10^{-11}$ & $1.97 \times 10^{-11}$ & $2.06 \times 10^{-11}$ \\
\hline
\end{tabular}

Table A.12: Thermal conductivity data for lunar simulant FJS-1 with three different densities (Wakabayashi and Matsumoto, 2006).

\begin{tabular}{c|ccc} 
& \multicolumn{3}{|c}{ Thermal Conductivity $(\mathrm{W} / \mathrm{m}-\mathrm{K})$} \\
Temp. (K) & $1.55 \mathrm{~g} / \mathrm{cm}^{3}$ & $1.65 \mathrm{~g} / \mathrm{cm}^{3}$ & $1.80 \mathrm{~g} / \mathrm{cm}^{3}$ \\
\hline 298 & $1.98 \times 10^{-2}$ & $2.33 \times 10^{-2}$ & $3.49 \times 10^{-2}$ \\
473 & $2.09 \times 10^{-2}$ & $2.44 \times 10^{-2}$ & $3.61 \times 10^{-2}$ \\
673 & $2.33 \times 10^{-2}$ & $2.56 \times 10^{-2}$ & $3.61 \times 10^{-2}$ \\
873 & $3.14 \times 10^{-2}$ & $3.49 \times 10^{-2}$ & $4.19 \times 10^{-2}$ \\
1073 & $4.42 \times 10^{-2}$ & $5.23 \times 10^{-2}$ & $5.70 \times 10^{-2}$ \\
1273 & $9.07 \times 10^{-2}$ & $1.14 \times 10^{-1}$ & $1.63 \times 10^{-1}$ \\
\hline
\end{tabular}


Table A.13: Data on the thermal conductivity $(\mathrm{W} / \mathrm{m}-\mathrm{K})$ for molten regolith analogs from various sources.

\begin{tabular}{|c|c|c|c|c|c|}
\hline \multicolumn{3}{|c|}{ Kang and Morita (2006) } & \multicolumn{3}{|c|}{$\begin{array}{c}\text { Snyder et al. }(1994) \\
\left(25-\mathrm{CaO} ; 25-\mathrm{MgO} ; 50-\mathrm{SiO}_{2}\right)\end{array}$} \\
\hline $\begin{array}{l}\text { Temp. } \\
(\mathrm{K})\end{array}$ & $\begin{array}{c}24-\mathrm{CaO} \\
15-\mathrm{Al}_{2} \mathrm{O}_{3} \\
61-\mathrm{SiO}_{2}\end{array}$ & $\begin{array}{c}26-\mathrm{CaO} ; \\
8-\mathrm{Al}_{2} \mathrm{O}_{3} ; \\
66-\mathrm{SiO}_{2}\end{array}$ & $\begin{array}{c}\text { Temp. } \\
(\mathrm{K})\end{array}$ & $\begin{array}{l}\text { Upper } \\
\text { Bound }\end{array}$ & $\begin{array}{l}\text { Lower } \\
\text { Bound }\end{array}$ \\
\hline 1573 & 1.5 & & 1673 & 0.35 & 0.2 \\
\hline 1623 & 1.4 & 0.9 & 1723 & 0.2 & 0.11 \\
\hline 1673 & 1.1 & 0.65 & 1773 & 0.19 & 0.12 \\
\hline 1723 & 0.75 & 0.5 & 1823 & 0.08 & 0.08 \\
\hline 1773 & 0.65 & 0.3 & 1873 & 0.07 & 0.04 \\
\hline 1823 & 0.6 & & & & \\
\hline 1873 & 0.35 & 0.2 & & & \\
\hline
\end{tabular}

Slag Atlas (Eisenhüttenleute, 1995)

\begin{tabular}{|c|c|c|c|c|}
\hline $\begin{array}{l}\text { Temp. } \\
(\mathrm{K})\end{array}$ & $\begin{array}{c}15-\mathrm{Al}_{2} \mathrm{O}_{3} \\
25-\mathrm{CaO} \\
60-\mathrm{SiO}_{2}\end{array}$ & $\begin{array}{c}24-\mathrm{CaO} \\
29-\mathrm{Fe}_{2} \mathrm{O}_{3} \\
47-\mathrm{SiO}_{2}\end{array}$ & $\begin{array}{l}49.5-\mathrm{CaO} \\
10-\mathrm{Fe}_{2} \mathrm{O}_{3} \\
40.5-\mathrm{SiO}_{2}\end{array}$ & $\begin{array}{c}20-\mathrm{Na}_{2} \mathrm{O} \\
80-\mathrm{SiO}_{2}\end{array}$ \\
\hline 1273 & 1.7 & 1.75 & 2.1 & 1.1 \\
\hline 1373 & 1.6 & 1.6 & 2 & 0.6 \\
\hline 1473 & 1.5 & 0.75 & 1.55 & 0.25 \\
\hline 1573 & 1.25 & 0.45 & 1 & 0.1 \\
\hline 1673 & 0.8 & 0.25 & 0.5 & \\
\hline 1773 & & 0.2 & 0.35 & \\
\hline
\end{tabular}


Table A.14: The electrical conductivity of lunar regolith analogs (all values are in $\mathrm{S} / \mathrm{m}$ ).

\begin{tabular}{|c|c|c|c|c|c|c|c|}
\hline \multicolumn{5}{|c|}{$\begin{array}{l}\text { Derived from Ducret et al. }(2002) \\
\left(25 \% \mathrm{CaO}, 25 \% \mathrm{MgO}, 50 \% \mathrm{SiO}_{2}\right)\end{array}$} & \multicolumn{3}{|c|}{ From Carroll (1983) } \\
\hline $\begin{array}{l}\text { Temp. } \\
(\mathrm{K})\end{array}$ & $\begin{array}{l}+0 \% \\
\mathrm{FeO}\end{array}$ & $\begin{array}{l}+5 \% \\
\mathrm{FeO}\end{array}$ & $\begin{array}{c}+10 \% \\
\mathrm{FeO}\end{array}$ & $\begin{array}{c}+15 \% \\
\mathrm{FeO}\end{array}$ & $\begin{array}{l}\text { Temp. } \\
(\mathrm{K})\end{array}$ & $\begin{array}{l}\text { Fe-rich } \\
\text { Basalt }\end{array}$ & Anorthite \\
\hline 1667 & 8.6 & 14.2 & 19.2 & 30.1 & 1473 & 8 & 1.3 \\
\hline 1695 & 10.5 & 16.5 & 22.3 & 35.0 & 1523 & 11.5 & 2 \\
\hline 1724 & 11.6 & 19.2 & 24.7 & 40.7 & 1573 & 15 & 3.3 \\
\hline 1754 & 15.0 & 21.2 & 28.7 & 44.9 & 1623 & 22 & 4.5 \\
\hline 1786 & 16.5 & 24.7 & 31.7 & 49.7 & 1673 & 30 & 6 \\
\hline 1818 & 20.2 & 28.7 & 36.8 & 54.9 & 1723 & 43 & 9 \\
\hline 1835 & 22.3 & 30.1 & 38.7 & 57.7 & & & \\
\hline 1852 & 22.8 & 33.3 & 42.7 & 60.7 & & & \\
\hline 1887 & 27.3 & 38.7 & 47.2 & 67.0 & & & \\
\hline 1923 & 33.3 & 47.2 & 54.9 & 77.9 & & & \\
\hline
\end{tabular}

\begin{tabular}{|c|c|c|c|c|c|c|}
\hline \multicolumn{4}{|c|}{ Derived from Rai (1977) } & \multicolumn{3}{|c|}{ Derived from Haskin et al. (1992) } \\
\hline $\begin{array}{l}\text { Temp. } \\
(\mathrm{K})\end{array}$ & $\begin{array}{c}\text { Tholeiitic } \\
\text { Basalt }\end{array}$ & $\begin{array}{l}\text { Temp. } \\
(\mathrm{K})\end{array}$ & $\begin{array}{l}\text { Alkalic } \\
\text { Basalt }\end{array}$ & Mineral & $\begin{array}{l}\text { Temp. } \\
(\mathrm{K})\end{array}$ & $\begin{array}{c}\sigma \\
(\mathrm{S} / \mathrm{m})\end{array}$ \\
\hline 1173 & 0.2 & 1373 & 0.6 & $\begin{array}{c}\text { Diopside ("Diop") } \\
\text { [CaMgSi2O8] }\end{array}$ & 1693 & 6 \\
\hline 1373 & 1.0 & 1413 & 2.5 & Diop $+0.5 \% \mathrm{FeO}$ & 1693 & 25 \\
\hline 1508 & 5.6 & 1448 & 3.2 & Diop $+5 \% \mathrm{FeO}$ & 1693 & 45 \\
\hline 1523 & 7.9 & 1473 & 3.5 & Diop $+20 \% \mathrm{Al}_{2} \mathrm{O}_{3}$ & 1693 & 5 \\
\hline 1667 & 10.0 & 1510 & 4.0 & 80 Ap15-20 Ilm & 1698 & 175 \\
\hline \multirow[t]{3}{*}{1773} & \multirow[t]{3}{*}{18.6} & 1639 & 10.0 & $\begin{array}{l}\text { Apollo } 15 \text { Mare } \\
\text { Analog ("Ap15") }\end{array}$ & 1698 & 50 \\
\hline & & \multirow[t]{2}{*}{1773} & \multirow[t]{2}{*}{15.8} & $\begin{array}{l}50 \% \text { Ap } 15 \\
50 \% \text { Ilmenite }\end{array}$ & 1823 & 475 \\
\hline & & & & Anorthite & 1823 & 9 \\
\hline
\end{tabular}


Table A.15: The regression coefficients for the low-temperature (top section) and hightemperature (bottom section) Gibbs Free Energy and Enthalpy of Formation fits shown in Equations (12) and (13). The maximum (minimum) temperature for the low (high) temperature data is shown on the right.

\section{Low Temperature Fits}

\begin{tabular}{lcccccc} 
Specie & $a_{G}$ & $b_{G}$ & $c_{G}$ & $a_{H}$ & $b_{H}$ & Max Temp $(\mathrm{K})$ \\
\hline $\mathrm{K}_{2} \mathrm{O}$ & -746.0 & -0.0820 & 0.5436 & -742.1 & 0.0333 & 1000 \\
$\mathrm{Na}_{2} \mathrm{O}$ & -766.9 & -0.1132 & 0.5769 & -767.6 & 0.0512 & 1100 \\
$\mathrm{P}_{2} \mathrm{O}_{5}$ & -1165 & -0.0030 & 0.3327 & -1164 & 0.0015 & 1100 \\
$\mathrm{FeO}$ & -497.9 & -0.0074 & 0.1243 & -500.8 & 0.0066 & 1800 \\
$\mathrm{Fe}_{2} \mathrm{O}_{3}$ & -552.2 & -0.0253 & 0.2538 & -551.1 & 0.0093 & 1800 \\
$\mathrm{Cr}_{2} \mathrm{O}_{3}$ & -678.6 & -0.0122 & 0.1839 & -676.9 & 0.0031 & 2100 \\
$\mathrm{SiO}_{2}$ & -906.3 & -0.0171 & 0.2301 & -906.5 & 0.0078 & 1600 \\
$\mathrm{TiO}_{2}$ & -896.7 & -0.0174 & 0.2152 & -899.0 & 0.0104 & 1900 \\
$\mathrm{Al}_{2} \mathrm{O}_{3}$ & -1074 & 0.0264 & 0.1140 & -1073 & -0.0131 & 1350 \\
$\mathrm{MgO}$ & -1056 & 0.0375 & 0.0528 & -1055 & -0.0186 & 1300 \\
$\mathrm{CaO}$ & -1104 & 0.0361 & 0.0421 & -1104 & -0.0154 & 1700 \\
\hline
\end{tabular}

\section{High Temperature Fits}

\begin{tabular}{lcccccc} 
Specie & $a_{G}$ & $b_{G}$ & $c_{G}$ & $a_{H}$ & $b_{H}$ & Min Temp $(\mathrm{K})$ \\
\hline $\mathrm{K}_{2} \mathrm{O}$ & -1182 & -0.3444 & 1.753 & -1184 & 0.1517 & 1000 \\
$\mathrm{Na}_{2} \mathrm{O}$ & -1196 & -0.2028 & 1.218 & -1196 & 0.0878 & 1100 \\
$\mathrm{P}_{2} \mathrm{O}_{5}$ & -1287 & -0.0521 & 0.5866 & -1286 & 0.0221 & 1100 \\
$\mathrm{FeO}$ & -522.9 & -0.0130 & 0.1561 & -522.9 & 0.0056 & 1800 \\
$\mathrm{Fe}_{2} \mathrm{O}_{3}$ & -552.5 & 0.0026 & 0.1632 & -552.4 & -0.0011 & 1800 \\
$\mathrm{Cr}_{2} \mathrm{O}_{3}$ & -728.6 & -0.0304 & 0.2684 & -728.6 & 0.0132 & 2100 \\
$\mathrm{SiO}_{2}$ & -974.5 & -0.0453 & 0.3612 & -974.3 & 0.0196 & 1600 \\
$\mathrm{TiO}_{2}$ & -913.6 & -0.0318 & 0.2711 & -913.5 & 0.0137 & 1900 \\
$\mathrm{Al}_{2} \mathrm{O}_{3}$ & -1154 & -0.1110 & 0.6038 & -1154 & 0.0481 & 1350 \\
$\mathrm{MgO}$ & -1412 & -0.1128 & 0.7845 & -1409 & 0.0479 & 1300 \\
$\mathrm{CaO}$ & -1494 & -0.0903 & 0.6732 & -1491 & 0.0377 & 1700 \\
\hline
\end{tabular}




\section{References}

Arndt, J., Flad, K., and Feth, M. (1979). Radiative cooling experiments on lunar glass analogues. In Lunar and Planetary Science Conference Proceedings, volume 10, pages 355-373.

Badescu, V. (2012). Moon: Prospective Energy and Material Resources. Springer.

Balasubramaniam, R., Gokoglu, S., and Hegde, U. (2010). The reduction of lunar regolith by carbothermal processing using methane. International Journal of Mineral Processing, 96(1):54-61.

Basu, A. and Riegsecker, S. (2000). Modal mineralogic distribution in the regolith at apollo landing sites. Journal of Geophysical Research: Planets (1991-2012), 105(E2):4361-4368.

Carroll, W. F. (1983). Research on the use of space resources. JPL Publication 83-36.

Chase, M. W. and Force, J. A. N. A. (1998). Nist-janaf thermochemical tables.

Colozza, A. J. (1991). Analysis of lunar regolith thermal energy storage. NASA STI/Recon Technical Report N, 92:14480.

Colson, R. O. and Haskin, L. A. (1990). Lunar oxygen and metal for use in near-earth space: Magma electrolysis. In In Arizona Univ., NASA Space Engineering Research Center for Utilization of Local Planetary Resources, volume 1.

Cremers, C. (1975). Thermophysical properties of apollo 14 fines. Journal of Geophysical Research, 80(32):4466-4470.

Ducret, A., Khetpal, D., and Sadoway, D. R. (2002). Electrical conductivity and transference number measurements of feo-cao-mgo-sio2 melts. In Electrochemical Society Meeting, Philadelphia, pages 347-53.

Eisenhüttenleute, V. D. (1995). Slag Atlas. Verlag Stahleisen GmbH. 
Fagents, S. A., Rumpf, M. E., Crawford, I. A., and Joy, K. H. (2010). Preservation potential of implanted solar wind volatiles in lunar paleoregolith deposits buried by lava flows. Icarus, 207(2):595-604.

Fulcher, G. S. (1925). Analysis of recent measurements of the viscosity of glasses. J. Am. Ceram. Soc., 8:339-355.

Haskin, L. A., Colson, R. O., Lindstrom, D. J., Lewis, R. H., and Semkow, K. W. (1992). Electrolytic smelting of lunar rock for oxygen, iron, and silicon. In Lunar Bases and Space Activities of the 21st Century, volume 1, pages $411-422$.

Heiken, G. H., Vaniman, D. T., and French, B. M. (1991). The Lunar sourcebook: A user's guide to the Moon. CUP Archive.

Hemingway, B., Robie, R., and Wilson, W. (1973). Specific heats of lunar soils, basalt, and breccias from the apollo 14, 15, and 16 landing sites, between 90 and $350 \mathrm{k}$. In Lunar and Planetary Science Conference Proceedings, volume 4, page 2481.

Horai, K.-i. (1981). The effect of interstitial gaseous pressure on the thermal conductivity of a simulated apollo 12 lunar soil sample. Physics of the Earth and Planetary Interiors, 27(1):60-71.

Kallerud, M., Nguyen, B., Paladin, T., and Wilson, A. (2011). In-situ resource utilization: Investigation of melted lunar regolith simulant jsc-1a. In Proceedings of the Wisconsin Space Conference.

Kang, Y. and Morita, K. (2006). Thermal conductivity of the cao-al2o3-sio2 system. ISIJ international, 46(3):420-426.

Kojitani, H. and Akaogi, M. (1995). Measurement of heat of fusion of model basalt in the system diopside-forsterite-anorthite. Geophysical research letters, 22(17):2329-2332.

Langseth Jr, M. G., Clark Jr, S. P., Chute Jr, J. L., Keihm, S. J., and Wechsler, A. E. (1972). The apollo 15 lunar heat-flow measurement. The Moon, 4(3-4):390-410.

Linne, D. L. (2010). Employing isru models to improve hardware design. In Proc., 48th AIAA Aerospace Sciences Meeting Including the New Horizons Forum and Aerospace Exposition. 
Lucey, P. G., Blewett, D. T., and Jolliff, B. L. (2000). Lunar iron and titanium abundance algorithms based on final processing of clementine ultraviolet-visible images. Journal of Geophysical Research: Planets (1991-2012), 105(E8):20297-20305.

Mueller, R. P., Townsend, I. I., Mantovani, J. G., and Metzger, P. T. (2010). Evolution of regolith feed systems for lunar isru o2 production plants. 48th AIAA Aerospace Sciences Meeting Including the New Horizons Forum and Aerospace Exposition.

Olhoeft, G., Frisillo, A., Strangway, D., and Sharpe, H. (1974). Temperature dependence of electrical conductivity and lunar temperatures. The moon, $9(1-2): 79-87$.

Planck, M. (1914). The theory of heat radiation. Masius (Blackiston, Philadelphia, 1914), Sec, 164:175.

Rai, C. S. (1977). Electrical and Elastic Properties of Basalts and Ultramafic Rocks as a Function of Saturation, Pressure and Temperature.

Richet, P. and Bottinga, Y. (1986). Thermochemical properties of silicate glasses and liquids: a review. Reviews of Geophysics, 24(1):1-25.

Richter, S. W. (1992). Experimental determination of in situ utilization of lunar regolith for thermal energy storage. Technical report, SAE Technical Paper.

Rumpf, M. E., Fagents, S. A., Crawford, I. A., and Joy, K. H. (2013). Numerical modeling of lava-regolith heat transfer on the moon and implications for the preservation of implanted volatiles. Journal of Geophysical Research: Planets, 118(3):382-397.

Schiefelbein, S. L. and Sadoway, D. R. (1997). A high-accuracy, calibrationfree technique for measuring the electrical conductivity of molten oxides. Metallurgical and Materials Transactions B, 28(6):1141-1149.

Schreiner, S., Sibille, L., Dominguez, J., Hoffman, J., Sanders, G., and Sirk, A. (2015). Development of a molten regolith electrolysis reactor model for lunar in-situ resource utilization. AIAA SciTech Conference - 8th Symposium on Space Resource Utilization. 
Sibille, L. and Dominguez, J. A. (2012). Joule-heated molten regolith electrolysis reactor concepts for oxygen and metals production on the moon and mars. 50th AIAA Aerospace Sciences Meeting including the New Horizons Forum and Aerospace Exposition.

Sirk, A. H., Sadoway, D. R., and Sibille, L. (2010). Direct electrolysis of molten lunar regolith for the production of oxygen and metals on the moon. ECS Transactions, 28(6):367-373.

Snyder, D., Gier, E., and Carmichael, I. (1994). Experimental determination of the thermal conductivity of molten camgsi2o6 and the transport of heat through magmas. Journal of Geophysical Research: Solid Earth (19782012), 99(B8):15503-15516.

Solomon, A., Alexiades, V., Jacobs, G., Naney, M., and Olszewski, M. (1992). Latent heat thermal energy storage for lunar oxygen production. In Fluid Mechanics Phenomena in Microgravity; ASME Winter Annual Meeting, volume 1, pages 8-13.

Standish, E. (2010). Design of a molten materials handling device for support of molten regolith electrolysis. $\mathrm{PhD}$ thesis, The Ohio State University.

Stebbins, J., Carmichael, I., and Moret, L. (1984). Heat capacities and entropies of silicate liquids and glasses. Contributions to mineralogy and petrology, 86(2):131-148.

Stoeser, D., Rickman, D., and Wilson, S. (2010). Design and specifications for the highland regolith prototype simulants NU-LHT-1M and-2M. Citeseer.

Tamman, G. and Heese, W. (1926). Die abhängigkeit der viscosität von der temperatur bie unterkühlten flüssigkeiten. Z. Anorg. Allg. Chem., 156:245257.

Taylor, L. A. and Carrier III, W. D. (1992). Production of oxygen on the moon: which processes are best and why. AIAA journal, 30(12):2858-2863.

Vila, J., Gines, P., Pico, J., Franjo, C., Jimenez, E., Varela, L., and Cabeza, O. (2006). Temperature dependence of the electrical conductivity in emimbased ionic liquids: evidence of vogel-tamman-fulcher behavior. Fluid Phase Equilibria, 242(2):141-146. 
Vogel, H. (1925). Phys. z. J. Am. Chem. Soc, 22:645-646.

Wakabayashi, S. and Matsumoto, K. (2006). Development of slope mobility testbed using simulated lunar soil. JAXA Research and Development Memorandum.

Watson, K. (1964). I. the thermal conductivity measurements of selected silicate powders in vacuum from 150-350 k, ii. an interpretation of the moons eclipse and lunation cooling as observed through the earths atmosphere from 8-14 microns. California Institute of Technology.

Zacny, K., Mueller, R., Galloway, G., Craft, J., Mungas, G., Hedlund, M., and Fink, P. (2009). Novel approaches to drilling and excavation on the moon. In AIAA SPACE Conference 6 Exposition, pages 6431-6443. 